\title{
Review: home or self blood pressure monitoring improves clinic blood pressure in essential hypertension
}

Cappuccio FP, Kerry SM, Forbes L, et al. Blood pressure control by home monitoring: meta-analysis of randomised trials. BMJ 2004;329:145.

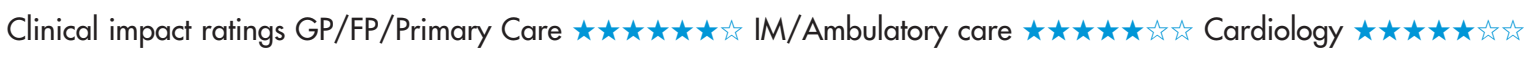

In people with essential hypertension, is home or "self" blood pressure (BP) monitoring more effective than usual BP monitoring in the healthcare system for improving BP control?

\section{METHODS}

Data sources: Medline (1966 to January 2003), EMBASE/
Excerpta Medica (1980 to January 2003), Cochrane Database of
Systematic Reviews, Database of Abstracts of Clinical
Effectiveness, Health Technology Assessment Database, National
Health Service Economic Evaluation Database, TRIP database,
websites for the Centre for Reviews and Dissemination and the
Agency for Healthcare Research and Quality, and bibliographies
of relevant articles.
$\begin{aligned} & \text { Study selection and assessment: randomised controlled trials } \\ & \text { (RCTs) that compared an intervention involving } \geqslant 1 \text { measurement } \\ & \text { of BP at home by study participants or their family members (and } \\ & \text { the result recorded by the participant or transmitted to a } \\ & \text { healthcare provider) with BP monitoring in the healthcare system } \\ & \text { as the control condition. } \\ & \text { Outcomes: change from baseline in systolic, diastolic, and mean } \\ & \text { BP (measured in a clinic by a healthcare provider) and number of } \\ & \text { patients with BP above a predetermined target. }\end{aligned}$

\section{MAIN RESULTS}

18 RCTs (2714 patients) met the selection criteria. Treatment in the control group was mainly usual or standard care (14 RCTs), but some RCTs had nurse clinics (2 RCTs), educational interventions (1 RCT), or flagged medical records ( 1 RCT). Meta-analyses were done using a random effects model. Reduction in systolic, diastolic, and mean arterial $\mathrm{BP}$ was greater in the intervention group than in the control group (table). However, after controlling for publication bias, the intervention effect was attenuated (table). Fewer patients in the intervention group than in the control group had BP measurements above predetermined targets (relative risk reduction 10\%, 95\% CI 0 to 20) (borderline significance $p=0.05$ ).

Home or self blood pressure monitoring $v$ usual blood pressure monitoring in the healthcare system in essential hypertension*

\begin{tabular}{ll}
\hline Outcomes at 2-36 months & $\begin{array}{l}\text { Weighted mean } \\
\text { difference }(95 \% \mathrm{Cl})\end{array}$ \\
\hline Systolic blood pressure $(\mathrm{mm} \mathrm{Hg})$ & $4.2(1.5$ to 6.9$) \dagger$ \\
Systolic blood pressure $(\mathrm{mm} \mathrm{Hg})$ & $2.2(-0.9$ to 5.3$) \ddagger$ \\
Diastolic blood pressure $(\mathrm{mm} \mathrm{Hg})$ & $2.4(1.2$ to 3.5$) \dagger$ \\
Diastolic blood pressure $(\mathrm{mm} \mathrm{Hg})$ & $1.9(0.6$ to 3.2$) \dagger \ddagger$ \\
Mean arterial blood pressure $(\mathrm{mm} \mathrm{Hg})$ & $4.4(2.0$ to 6.8$) \dagger$ \\
\hline
\end{tabular}

*Meta-analyses were done using a random effects model. $\mathrm{Cl}$ defined in glossary.

†Significant differences favour home or self blood pressure monitoring flntervention effect after controlling for publication bias.

For correspondence: Professor F P Cappuccio, St George's Hospital Medical School, London, UK. f.cappuccio@sghms.ac.uk

Source of funding: no external funding.

\section{CONCLUSIONS}

In people with essential hypertension, home or self blood pressure monitoring is more effective than usual blood pressure monitoring in the healthcare system for improving blood pressure control.

\section{Commentary}

$\mathrm{P}$ roperly done home BP measurements accurately reflect daytime BP and can help in the care of people with high office readings. Some of these patients have home BP consistently $<135 / 85$ but have white coat hypertension, although confirmatory automated ambulatory recordings are sometimes needed.' Others have established hypertension, and ongoing home monitoring can provide better measures of control than are afforded by office readings and promote treatment adherence by involving patients in their own care.

Cappuccio et al reviewed 18 RCTs to assess the effect of adding home monitoring to office care in the care of patients with established hypertension, with office BP readings as the outcome of interest. Overall, systolic BP was $4.2 \mathrm{~mm} \mathrm{Hg}$ lower in the intervention group than in the control group, but this effect was reduced to only $2.2 \mathrm{~mm} \mathrm{Hg}$ after correction for publication bias. Fewer patients in the intervention group than in the control group had BP measurements above predetermined targets, but this result was barely significant. Small reductions in BP when applied to populations can cause dramatic reductions in cardiovascular events, ${ }^{2}$ but this was not directly tested in the studies reviewed. Mechanisms of benefit could have included better adherence, quicker titration of drugs, and an overcoming of clinician inertia in making treatment changes.

Challenges to the conclusions of this meta-analysis lie in the range of BP definitions, treatments, and targets used in the studies reviewed. Extrapolation to any contemporary population, using current BP goals, is difficult. These goals are moving targets, and how much home monitoring will help in treating patients to achieve standards set out in the Joint National Committee 7 report $^{3}$ is hard to tell from this review. I agree with the authors that outcome data from prospective contemporary studies are needed.

Until then, home BP monitoring can be seen as a safe and inexpensive adjunct in the care of patients with hypertension. ${ }^{4}$ Its greatest value may well lie in motivating patients to become real partners in their care.

David R Gutknecht, MD Geisinger Medical Center Danville, Pennsylvania, USA

1 White WB. Ambulatory blood-pressure monitoring in clinical practice. N Engl J Med 2003;348:2377-8.

2 Collins R, Peto R, MacMahon S, et al. Blood pressure, stroke, and coronary heart disease. Part 2, short term reductions in blood pressure: overview of randomised drug trials in their epidemiological context. Lancet 1990;335:827-38.

3 Chobanian AV, Bakris GL, Black HR, et al. The Seventh Report of the Joint National Committee on prevention, evaluation, and treatment of high blood pressure: the JNC 7 report. JAMA 2003;289:2560-72.

4 Stergiou G, Mengden T, Padfield PL, et al. Self monitoring of blood pressure at home. BMJ 2004;329:870-1. 